Volume 9, No.5, September - October 2020

International Journal of Advanced Trends in Computer Science and Engineering

Available Online at http://www.warse.org/IJATCSE/static/pdf/file/ijatcse80952020.pdf

https://doi.org/10.30534/ijatcse/2020/80952020

\title{
An Alternative Algorithm to Invasive Weed Optimization Based Global Maximum Power Point Tracking for PV Array Under Partial Shading Conditions
}

\author{
Hegazy Zaher ${ }^{1}$, Mohamed Husien Mohamed Eid ${ }^{2}$, Radwa. S. A. Gad ${ }^{* 3}$, I. M. Abdelqawee ${ }^{4}$ \\ ${ }^{1}$ Faculty of Graduate Studies for Statistical Research, Affiliated to Cairo University, Egypt, Hgsabry@ yahoo.com. \\ ${ }^{2}$ Physics and Engineering Mathematics Dept., Affiliated to Shoubra Faculty of Engineering, Benha University, \\ Egypt, mohamed.eed@feng.bu.edu.eg. \\ ${ }^{3}$ Physics and Engineering Mathematics Dept., Affiliated to Shoubra Faculty of Engineering, Benha University, \\ Egypt, radwa.gad@feng.bu.edu.eg. \\ ${ }^{4}$ Electrical Engineering Dept., Affiliated to Shoubra Faculty of Engineering, Benha University, Egypt, \\ islam.ahmed@feng.bu.edu.eg.
}

\begin{abstract}
In this study, a global maximum power point tracking technique based on invasive weed optimization algorithm for $\mathrm{PV}$ array under partial shading conditions is proposed. This technique is not used before with this problem. The power-voltage curve of the PV array has several local maximum power points. The proposed method converges successfully to the global maximum. An overall statistical appraisal of the proposed technique compared with different meta-heuristic techniques mentioned in literature is executed under di $\square$ erent scenarios of shading conditions to estimate the superiority of the proposed technique over all other techniques. The statistical metrics are including geometric mean, the root mean square error, mean absolute error, standard deviation, arithmetic mean, significance, and $\mathrm{e} \square$ ciency, in addition to a proposed one for measuring solution stability. The proposed algorithm is considered to be the most efficient and outstanding optimization technique compared to corresponding ones.
\end{abstract}

Key words: PV systems; Global maximum power point tracking; partial shading; Invasive Weed; Modern Optimization.

\section{INTRODUCTION}

One of the hot topics of research in the improvement of PV system efficiencies is the maximum power point tracking (MPPT). In the beginning, conventional MPPT techniques such as perturb and observe $(\mathrm{P} \& \mathrm{O})$, incremental conductance (IC), hill climbing and constant voltage techniques are used for several years to do the job of MPPT under uniform radiation [1].

Due to partial shading conditions (PSCs), which can create one Global Maximum Power Point (GMPP) and multiple
Local Maximum Power Points (LMPPs), these techniques are likely to be trapped at one of the LMPPs as these algorithms could not characterize between GMPP and LMPPs [2].

To overcome this problem, global MPPT techniques based on Meta-Heuristic optimization algorithms such as Particle Swarm Optimization (PSO), Differential Evolution (DE), Harmony Search Algorithm (HSA), Bat Algorithm (BA), Sine Cosine Algorithm (SCA), Wind Driven Optimization (WDO), Cuckoo Search (CS) and Genetic Algorithm (GA) are previously developed [3].

Meta-heuristic techniques, which depends on many searching criteria, send searching agents to search global maximum power and adjust the new positions of the searching agents to follow the highest possible values caught in the previous positions. Although most of the meta-heuristic techniques can reach the GMPP under uniform and PSCs, these techniques suffer from some problems [4].

For example, GA can handle the MPPT control in PV systems operating under partial shaded conditions. Although GA distinguishes by fit solutions that can be found in a very less time and easy coding compared to other algorithms which does the same job, it has drawback, which is not finding the most optimal solution to the defined problem in all cases [5]. Due to its faster tracking, better efficiency and a reduction in PV output power oscillations due to PSCs which ultimately reduces the loss in performance faced by the conventional algorithms, PSO is proposed. Although PSO can deal with optimization problems of large dimensions, often producing quality solutions more rapidly than alternative methods, it suffers from no general convergence theory for practical, multidimensional problems and tuning of input parameters [6]. DE is applied in the MPPT controller for the PV modules under PSCs. The technique has higher efficiency, ease of implementation, the feasibility and keeping the multiplicity of population and enhancing the capacity of local search. Although the previous merits of $\mathrm{DE}$, its convergence is unstable and easy to drop into the $p_{\text {best }}$ [7]. Due to its reliability under variable irradiance, variable temperature and variable 
PV rating, HSA is proposed for PSCs. Despite HSA produces better solution than other existing algorithm in less number of iterations and not needing initial value for decision variables, it suffers from the problem of premature and/or false convergence and slow convergence especially over multimodal fitness landscape [8]. On other hand, CS is able to track the MPP efficiently. Although the simplicity, easiness to implement, dealing with multi-criteria optimization problems and hybridization with other swarm-based algorithms of CS, it suffers from bad accuracy, low convergence rate and easiness fall into local optimal value [9]. A fast-converging BA is able to track the GMPP for a PV array subjected to PSCs. BA is more efficient, faster, sustainable and more reliable for PV systems subjected to intensive PSCs. Even though the previous merits, BA suffers from leading to stagnation after some initial stage if we allow the algorithm to switch to exploitation stage too quickly by varying loudness and rate of pulse emission too quickly [10]. WDO presents a robust global MPPT technique for PV system under non-uniform solar irradiance. Despite easiness of WDO to carried out, WDO suffers from low convergence speed and Trapped on local optima [11]. Although the SCA has providing simple implementation strategy, better tracking ability, high convergence rate. Unfortunately, it suffers from its disability to transcend other algorithms on specific set of problems and existence of four random parameters [12].

Despite the merits of various meta-heuristic optimization techniques in the literature, it has been demonstrated by the No-Free-Lunch [4], that none of them are able to solving all optimization problems. This clearly detects the importance of finding new algorithms to deal with all concerned related issues in di $\square$ erent fields. Despite the validation of an algorithm in solving set of problems does not promise its accommodation in different sets of test problems, for example, the invasive weed optimization (IWO) algorithm by (Mehrabian and Lucas, 2006) didn't utilize in the field of MPPT for partially shaded PV systems. This algorithm compared to similar particle-based algorithms has a powerful advantageous as it robust, stochastic, and derivative free optimization algorithm for the solution of complex real-world problems. This encourages us to use IWO for first time in solving the problem of PSC of PV systems [13].

\section{PV UNDER PARTIAL SHADING}

A PV array consisting of four modules connected in series in different cases is shown in Figure 1. Figure 1 (a) shows unshaded PV array on the other side Figure1 (b, c, d) shows a partially shaded PV array in different scenarios. The equivalent circuit of PV array is shown in Figure 2.

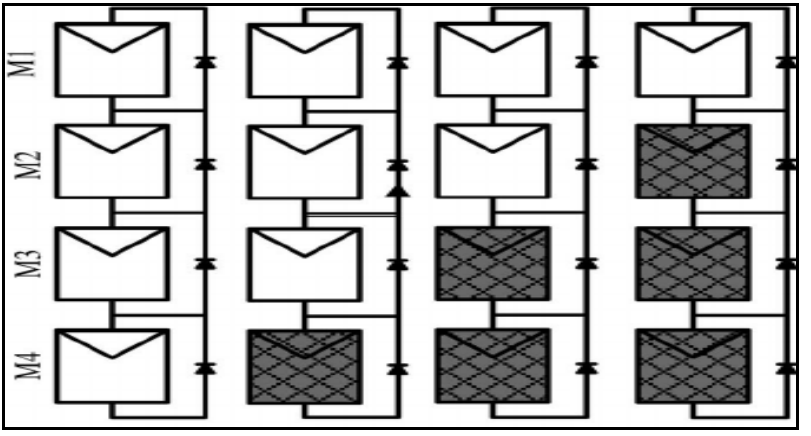

(a)

(b)

(c)

(d)

Figure 1: (a) Unshaded PV array, (b, c, d) Shaded PV array

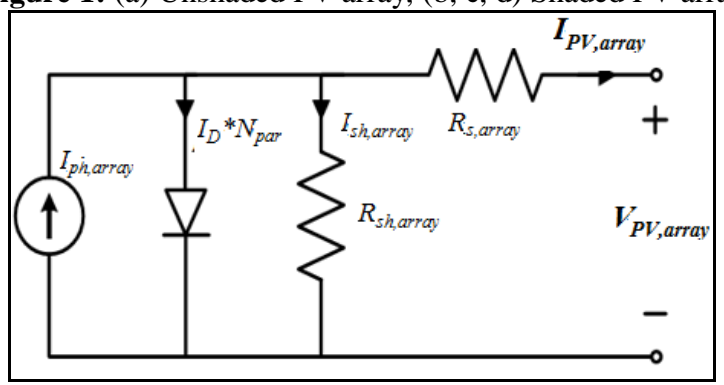

Figure 2: Equivalent circuit of $\mathrm{PV}$ array

The optimal value from the PV array under partial shading will be reached by maximizing the expected power from the PV system by using the following objective function [14]:

Maximize: $\quad P_{p v, \text { array }}=I_{p v, \text { array }} * V_{p v, \text { array }}$

Where:

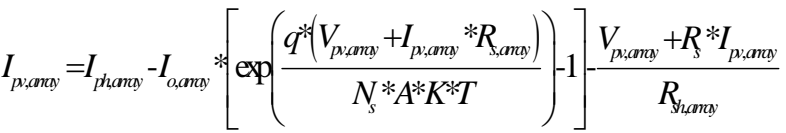

$$
\begin{aligned}
& I_{p h, a r a y}=\left(I_{s c}(T)_{a r r a y}+K_{i} *\left(T_{a k}-T_{r k}\right)\right) * \frac{G}{G_{S T C}} \\
& I_{o, a n y y}=\left[I_{s c}(T)-\frac{V_{\alpha}(T)_{a n y}-I_{s c}(T)_{a n x y} * R_{s, a n y y}}{R_{s, a n y y}}\right] * \exp \left(-\frac{V_{\alpha}(T)_{a n y y}}{A^{*} N_{s}^{*} V_{t}}\right)
\end{aligned}
$$

Where the parameters:

$$
I_{p h, \text { array }}, I_{o, \text { array }}, V_{P V, \text { array }}, R_{s, \text { aray }} \text {, and } R_{s h, \text { array }}
$$

may be expressed as:

$I_{p h, \text { array }}=I_{p h} * N_{p a r}$, and $I_{\text {o.aray }}=I_{o} * N_{p a r}$,

$V_{o c, a r c y}(T)=V_{o c}(T) * N_{s e r}$,

$V_{o c}(T, G)=V_{o c}+k_{v}\left(T-T_{s t c}\right)+N_{s} A(T) V_{t} \ln \left(\frac{G}{G_{s t c}}\right)$

$I_{s c}(T)=I_{s c}+K_{i} *\left(T_{a k}-T_{r k}\right)$,

$R_{s, \text { aray }}=R_{s} *\left(N_{s e r} / N_{p a r}\right)$, and $R_{s h, a r a y}=R_{s h} *\left(N_{s e r} / N_{p a r}\right)$.

Where,

$N_{s e r}$ : Number of series modules.

$N_{\text {par }}$ : Number of parallel modules.

$N_{s}$ : Number of cells in one module.

$A$; Ideality factor of diode, $A(T)=A *\left(T_{\text {std }} d T\right)$.

$T, T_{\text {stc }}$ : The temperature of the PV array under normal 
operation and at standard test condition.

$G, G_{s t c}$ : Irradiance level under normal operation and at standard test condition, $\mathrm{W} / \mathrm{m}^{2}$.

$K$ : Boltzmann's constant, $1.3805^{*} 10^{-23} \mathrm{~J} / \mathrm{K}$.

$q$ : Electron charge, $1.6 * 10^{-19} c$.

$R_{s}, R_{s h}$ : Panel series resistance and parallel (shunt) resistance.

$V_{o c}$ : Open circuit voltage.

$I_{s c}:$ Short circuit current.

$T_{a k}, T_{r k}$ : Actual and Relative temperature in Kelvin.

$K_{v}$ and $K_{i}::$ Temperature coefficient of $V_{o c}$ and $I_{s c}$

$V_{t}$ : The junction thermal voltage, $\left(K^{*} T_{a k}\right) / q$.

Due to the presence of PSC [4], several peaks divided into one GMPP and several LMMPs appear on the expected power curve from the PV array under PSC as shown in Figure 3 in which there are three curves, the $1^{\text {st }}$ under no partial shading under STC $\left(25^{\circ} \mathrm{C}, 1000 \mathrm{~W} / \mathrm{m}^{2}\right.$ applied to the four arrays), the $2^{\text {nd }}$ under PSC $(1)$ under $\left(25^{\circ} \mathrm{C},[1000800700600]\right)$ and the $3^{\text {rd }}$ under PSC(2) under (25 C, [900 700400 200]).

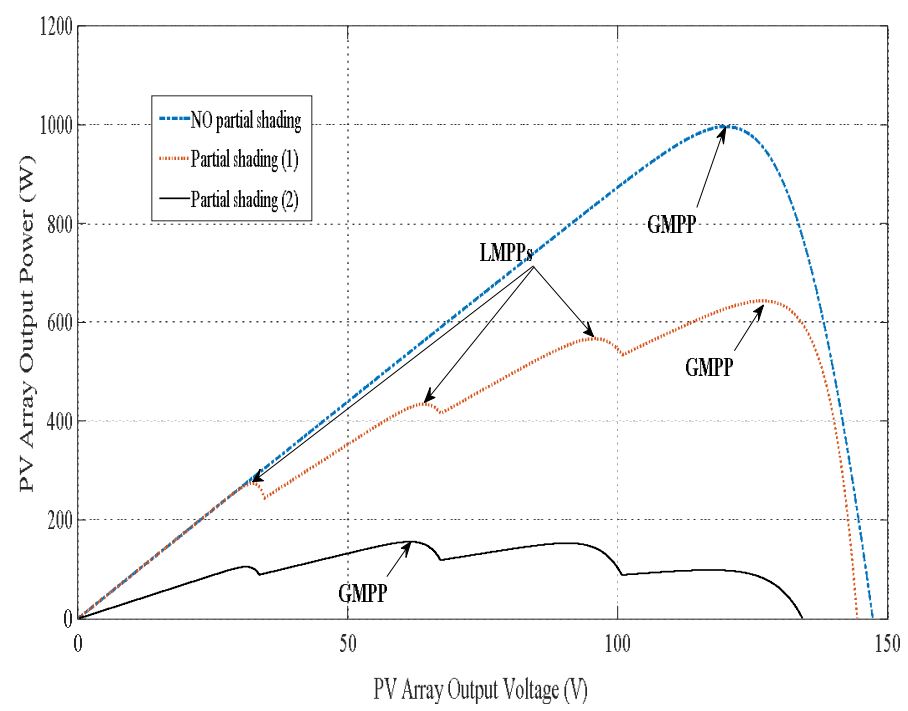

Figure 3: The expected power from the PV system under partial shading

\section{PROPOSED IWO TECHNIQUE}

Invasive weed optimization algorithm was first proposed by Mehrabian and Lucas (2006), [15]-[17]. The idea of IWO algorithm originates from the evolution principle of weeds in nature, which is implemented by the simulation of five basic steps, initialization, reproduction, spatial dispersal, competitive exclusion and termination condition. The basic IWO algorithm can be briefed as follows:

1) Initialization a population: A population of a set of initial solution i.e. seeds are randomly dispreads over the search space with random positions. The dimension of the search space is determined by the numbers of variables.

2) Reproduction: The fitness values of the seeds are evaluated. At this stage, the seeds have grown to become weeds. These weeds are ranked on the basis of their fitness values in the colony. Now each weed is capable of producing new seeds according to its rank. Higher is the fitness of the weed, more is the numbers of seeds produced by the weed. The number of seeds produced by each weed is given by [16]:

$$
\text { Weed }_{n}=\frac{f-f_{\text {min }}}{f_{\text {max }}-f_{\text {min }}}\left(s_{\text {max }}-s_{\text {min }}\right)+s_{\text {min }}
$$

Where $f$ is the fitness of the current weed. $f_{\min }$ and $f_{\max }$ respectively represent the least fitness and the maximum of the current population. $s_{\min }$ and $s_{\max }$ respectively represent the least and the maximum value of a weed.

3) Spatial dispersal: The seeds so produced are scattered over the search space around their parent by means of normal distribution with zero mean and changing variance. The normal distribution guarantee that the generated seeds are distributed near to their parent. But the standard deviation $\sigma$ of random function goes on reducing from previously defined initial value $\sigma_{\text {init }}$ to final value $\sigma_{\text {final }}$ with the increase of number of iterations so that the technique can gradually move from exploration to exploitation. For a given iteration, the standard deviation of the random function is given by [16]:

$$
\sigma_{\text {iter }}=\left(\frac{\text { iter }_{\max }-i t e r}{i t e r_{\max }}\right)^{n} \times\left(\sigma_{\text {init }}-\sigma_{\text {final }}\right)+\sigma_{\text {final }}
$$

Where $\sigma_{i t e r}$ is the standard deviation at the current iteration iter, and iter $_{\text {max }}$ is the maximum number of iterations, and $n$ is a nonlinear modulation index having the value in the range of 2 to 3 .

4) Competitive exclusion: After passing some iteration, all of the weeds and their seeds are combined together to form a population for the next generation. If the number of weeds in a colony will exceed its maximum $\left(P_{\max }\right)$ by fast reproduction, weeds with lower fitness are eliminated to reach the maximum allowable population in a colony. In this way, weeds and seeds are classified together and the ones with higher fitness survive and are permitted to reproduce. The reproduction and competitive processes give an opportunity for less fit weeds to reproduce. If they reproduce fitter offspring, the offspring can survive in the competition.

5) Termination condition: This operation continues until a given termination condition, such as the maximum number of iterations, or another terminating criterion, is reached.

In this case of study of global MPPT, a weed in a colony represents a voltage of the PV array since, the weed of higher fitness represented the voltage at which the global power point. Figure 4 shows the searching mechanism flowchart that is done by IWO for the purpose of MPPT tracking. 


\section{COMPARATIVE STUDY}

The validation of the proposed technique was presented in four different case studies. A comparative study was performed with others optimization techniques to validate it. Four Kyocera KD135SX-UPU PV modules were used to study the partial shading conditions. The specifications of this module are given in Table 1.

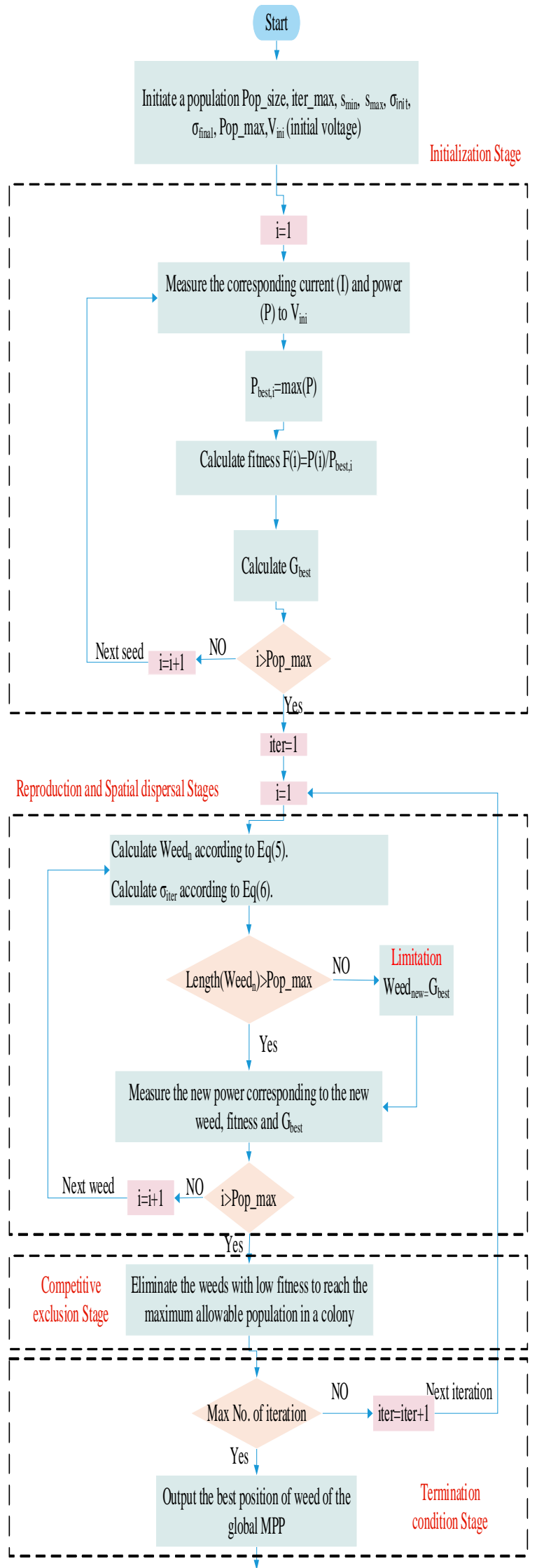

End

Figure 4: IWO algorithm 
Table 1: PV module specifications

\begin{tabular}{l|c}
\hline \multicolumn{1}{c|}{ Type } & $\begin{array}{c}\text { Kyocera } \\
\text { KD135SX-UPU }\end{array}$ \\
\hline Maximum power, $\boldsymbol{P}_{\max }$ & $135 \mathrm{~W}$ \\
\hline Open circuit voltage, $\boldsymbol{V}_{\boldsymbol{o c}}$ & $22.1 \mathrm{~V}$ \\
\hline Voltage at maximum power point & $17.7 \mathrm{~V}$ \\
\hline Short circuit current, $\boldsymbol{I}_{\boldsymbol{s c}}$ & $8.37 \mathrm{~A}$ \\
\hline $\begin{array}{l}\text { Current at maximum power } \\
\text { point }\end{array}$ & $7.63 \mathrm{~A}$ \\
\hline $\begin{array}{l}\text { Short circuit current } \\
\text { temperature coe } \square \text { cient, } \boldsymbol{K}_{\boldsymbol{i}}\end{array}$ & $5.02^{*} 10^{-3} \mathrm{~A} / \mathrm{C}$ \\
\hline $\begin{array}{l}\text { Open circuit voltage temperature } \\
\text { coe } \square \text { cient, } \boldsymbol{K}_{\boldsymbol{v}}\end{array}$ & $-8^{\circ} 10^{-2} \mathrm{~V} /{ }^{\circ} \mathrm{C}$ \\
\hline Reference temperature, $\boldsymbol{T}_{\text {ref }}$ & $25^{\circ} \mathrm{C}$ \\
\hline
\end{tabular}

It is observed from the prior studies that most research had considered just a single radiation model or few models of PSC to check the strength of the optimization technique for tracking the global MPP without an extensive statistical analysis (i.e. only one run for each technique). This in turns encouraged the authors to put in a global arbitrage via an extensive statistical analysis of di $\square$ erent global MPPT techniques based on modern optimization algorithms. In this study, every technique is verified for 50 runs in order to evaluate and validate the performance of each one. The worthy eight statistical metrics for this evaluation are; the Geometric mean (GM) which is an important parameter in our comparison and considered to be the best average for the construction of index numbers as it is suitable for measuring the relative changes and it gives more weights to the small values and less weights to the large values [18], Root Mean Square Error (RMSE), Mean Absolute Error (MAE), Standard Deviation (SD), Arithmetic Mean (AM), stability which is defined as the difference between AM and GM, The smaller value of stability indicates more solution stability, significance using $\mathrm{z}$ value and $\mathrm{e} \square$ ciency. These metrics can be estimated as the following [11], [19].

$$
\begin{aligned}
& A M=\frac{\sum_{i=1}^{n_{r}} P_{p v e, i}}{n_{r}} \\
& G M=\sqrt[n_{r}]{\prod_{i=1}^{n_{r}} P_{p v e, i}} \\
& R M S E=\sqrt{\frac{\sum_{i=1}^{n_{r}}\left|P_{p v e, i}-P_{p v t}\right|^{2}}{n_{r}}} \\
& M A E=\frac{\sum_{i=1}^{n_{r}}\left|P_{p v e, i}-P_{p v t}\right|}{n_{r}}
\end{aligned}
$$

$$
\begin{aligned}
& S D=\sqrt{\frac{\sum_{i=1}^{n_{r}}\left|A M-P_{p v e, i}\right|^{2}}{n_{r}}} \\
& \text { Stability }=\left(1-\frac{A M-G M}{R M S E}\right) * 100 \\
& \text { Efficiency }=\frac{G M}{P_{p v t}} * 100 \\
& \text { z value }=\frac{\left|B_{w}-B_{c}\right|}{\sqrt{\frac{B_{w}\left(1-B_{w}\right)}{N_{w}}+\frac{B_{c}\left(1-B_{c}\right)}{N_{c}}}}
\end{aligned}
$$

Where

$n_{r}$ : represents the number of the model runs.

$P_{p v e, i}$ : current value of obtained PV power by optimizer for each run.

$P_{p v t}:$ theoretical global PV power.

$N_{w}$ : The number of reaches to GMPP of IWO.

$N_{c}$ : The number of reaches to GMPP of comparative technique with IWO.

$B_{w}$ : The percentage of reach to GMPP of IWO, $N_{w} / n_{r}$.

$B_{c}$ : The percentage of reach to GMPP of comparative technique with IWO, $N_{c} / n_{r}$

If $\mathrm{z}$ value is higher than 1.96 , this indicates that there is a significance between IWO and the comparative technique [19]. The authors in [11] investigate the problem of MPPT of PV array under PSCs using PSO, GA, WDO, HSA, SCA, BA, $\mathrm{DE}$ and CS. In this paper, the results of proposed technique are compared with the results of these eight techniques.

The input parameters for each optimization technique are shown in Table 2. Two different scenarios of shading are considered. The idea of changing shading models is to change the location of global MPP from left to right or middle to measure the response of each technique with different cases and affirmation of its stable quality for tracking the global MPP. Two different PV system formations are considered: the first one contains three series connected PV modules whereas the second comprises four series connected PV modules. Two

\begin{tabular}{|c|c|c|c|c|}
\hline \multicolumn{2}{|l|}{ GA [14] } & \multicolumn{3}{|c|}{ CS [14] } \\
\hline Crossover Rate & 0.8 & $\lambda$ & Constant & 1.5 \\
\hline Mutation rate & 0.1 & & & \\
\hline \multicolumn{2}{|l|}{ PSO [14] } & \multicolumn{3}{|c|}{$\mathrm{BA}[14]$} \\
\hline Inertia weight & 0.4 & $A$ & Loudness & 0.7 \\
\hline Random value & {$[0,1]$} & $r$ & Pulse rate & 0.5 \\
\hline$r_{2} \quad$ Random value & {$[0,1]$} & $f_{\min }$ & Min frequency & 0 \\
\hline$c_{1} \quad$ Cognitive coeffic & ient 1 & $f_{\max }$ & Max frequency & y 1 \\
\hline
\end{tabular}
different partial shading scenarios are considered according to table 3. Figure 5 shows that the first scenario are applied to first PV array formation. The solar irradiance levels of 1000, $800,600 \mathrm{~W} / \mathrm{m}^{2}$ are subjected to first PV modules in the first scenario. While the second scenario is done with the second PV system.

Table 2: Input parameters for each optimization technique 


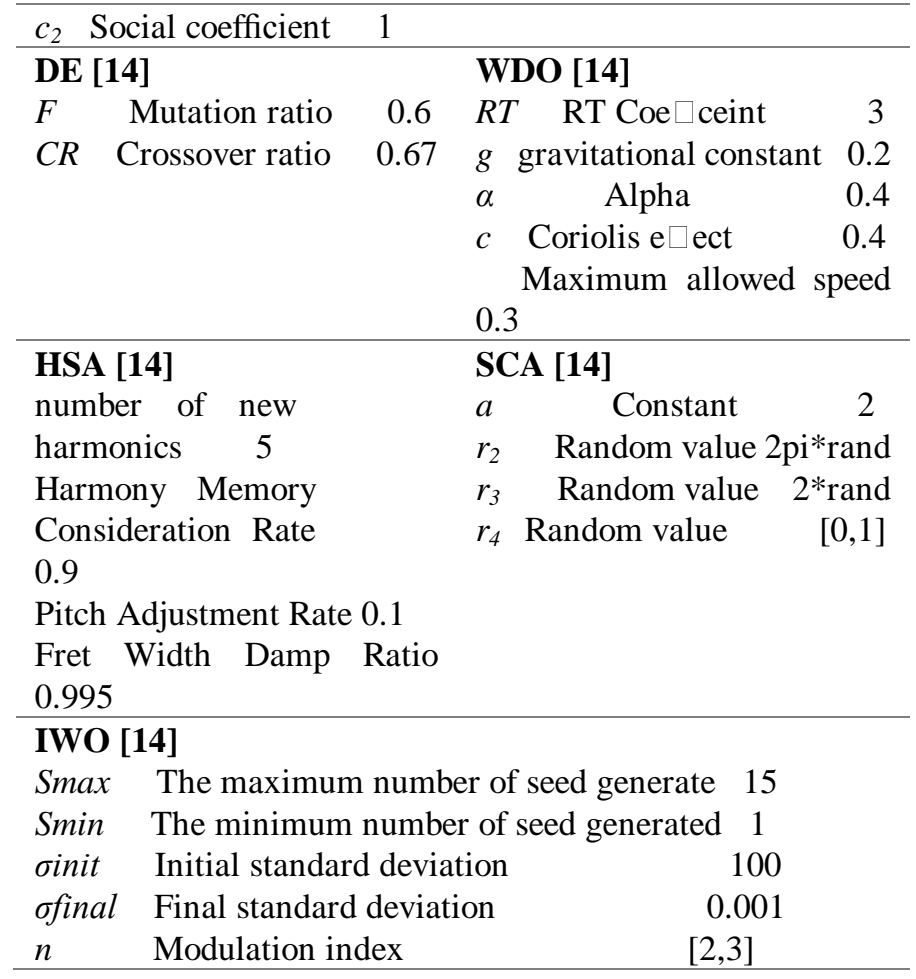

Table 3: The PV array with di $\square$ erent shading scenarios

\begin{tabular}{|c|l|l|l|l|}
\hline $\begin{array}{l}\text { Scenario } \\
\text { number }\end{array}$ & $\begin{array}{l}\text { PV array } \\
\text { structure }\end{array}$ & $\mathrm{G}\left(\mathrm{W} / \mathrm{m}^{2}\right)$ & $\begin{array}{l}\text { Power at } \\
\text { MPP, W }\end{array}$ & $\begin{array}{l}\text { Position } \\
\text { of GMPP }\end{array}$ \\
\hline 1 & Three & $1000,800,600$ & 255.7 & Right \\
\hline 2 & Four & $\begin{array}{l}900,700,400, \\
200\end{array}$ & 196.4 & $2^{\text {nd }}$ left \\
\hline
\end{tabular}
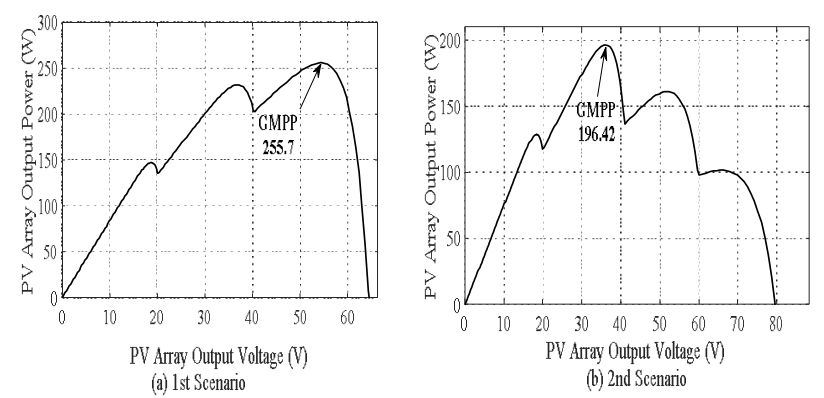

Figure 5: The P-V curves of the studied PV array with di $\square$ erent shading scenarios

\section{SIMULATION AND DISCUSSION}

To analyze and estimate the performance of the presented algorithms, the algorithms parameters are set to be; population size $=5$, and no. of executions for each algorithm (50 times, i.e. 50 run). The detailed performance of each technique for the different scenarios are shown from table 4 to table 5. Table 6 shows the number of reaches to GMPP for each technique. The statistical measured performance evaluation for each technique under different shadow scenarios is summarized in table 7 . Finally, table 8 shows the significance of IWO compared to the previously developed techniques using z-value. 
Hegazy Zaher et al., International Journal of Advanced Trends in Computer Science and Engineering, 9(5), September - October 2020,7467 - 7477 Table 4: The detailed performance of each technique for the $1^{\text {st }}$ shading scenario.

\begin{tabular}{|c|c|c|c|c|c|c|c|c|c|}
\hline Runs & DE & HSA & PSO & CS & SCA & GA & Bat & WDO & IWO \\
\hline 1 & 255.7 & 250.73 & 255.7 & 255.7 & 249.42 & 254.58 & 252.01 & 255.57 & 255.7 \\
\hline 2 & 255.7 & 216.15 & 255.69 & 255.7 & 255.16 & 255.7 & 255.64 & 255.66 & 255.7 \\
\hline 3 & 255.7 & 255.7 & 255.7 & 255.7 & 255.69 & 255.4 & 250.99 & 255.7 & 255.7 \\
\hline 4 & 255.66 & 251.93 & 255.7 & 255.7 & 255.2 & 255.69 & 249.47 & 255.68 & 255.7 \\
\hline 5 & 255.7 & 245.85 & 255.7 & 255.7 & 254.14 & 255.57 & 255.63 & 255.69 & 255.7 \\
\hline 6 & 255.7 & 228.41 & 255.69 & 255.7 & 255.7 & 255.65 & 255.62 & 254.49 & 255.7 \\
\hline 7 & 255.7 & 255.35 & 255.7 & 255.7 & 253.99 & 255.7 & 252.87 & 255.7 & 255.7 \\
\hline 8 & 255.7 & 255.01 & 255.61 & 255.7 & 255.67 & 255.55 & 232.32 & 255.66 & 255.7 \\
\hline 9 & 255.7 & 242.09 & 208.13 & 255.7 & 255.62 & 255.69 & 255.28 & 255.53 & 255.7 \\
\hline 10 & 255.69 & 248.16 & 255.7 & 255.7 & 253.43 & 255.69 & 255.43 & 255.68 & 255.7 \\
\hline 11 & 255.7 & 242.27 & 255.68 & 255.7 & 253.41 & 255.69 & 249.65 & 255.7 & 255.7 \\
\hline 12 & 255.7 & 255.63 & 255.55 & 255.7 & 253.61 & 255.66 & 255.68 & 255.39 & 255.7 \\
\hline 13 & 255.69 & 241.26 & 255.68 & 255.7 & 252.97 & 255.33 & 253.96 & 255.61 & 255.7 \\
\hline 14 & 255.69 & 255.69 & 208.14 & 255.7 & 240.48 & 254.84 & 254.77 & 255.69 & 255.7 \\
\hline 15 & 224.58 & 252.84 & 255.7 & 255.7 & 254.5 & 255.51 & 255.56 & 255.68 & 255.7 \\
\hline 16 & 255.7 & 243.4 & 255.69 & 255.7 & 255.68 & 255.4 & 254.51 & 255.56 & 255.7 \\
\hline 17 & 224.65 & 215.86 & 255.7 & 255.7 & 255.34 & 253.54 & 255.7 & 255.7 & 255.7 \\
\hline 18 & 255.59 & 248.93 & 255.7 & 255.7 & 254.85 & 254.83 & 253.03 & 255.69 & 255.7 \\
\hline 19 & 242.28 & 255.67 & 255.7 & 208.16 & 253.44 & 255.7 & 255.69 & 255.67 & 255.7 \\
\hline 20 & 255.7 & 254.74 & 224.66 & 208.16 & 252.55 & 255.61 & 255.68 & 255.58 & 255.7 \\
\hline 21 & 255.7 & 248.79 & 255.67 & 255.7 & 251.96 & 255.7 & 223.79 & 255.38 & 255.7 \\
\hline 22 & 255.67 & 225.85 & 255.7 & 255.7 & 245.44 & 255.7 & 254.04 & 255.69 & 255.7 \\
\hline 23 & 255.7 & 245.24 & 255.7 & 255.7 & 250.12 & 255.7 & 236.86 & 255.66 & 255.7 \\
\hline 24 & 255.7 & 254.53 & 255.69 & 255.7 & 254.76 & 255.62 & 255.69 & 255.69 & 255.7 \\
\hline 25 & 255.64 & 240.43 & 255.69 & 255.7 & 242.14 & 255.7 & 255.65 & 224.66 & 252.09 \\
\hline 26 & 255.67 & 255.65 & 255.7 & 255.7 & 254.48 & 255.7 & 255.4 & 255.59 & 255.7 \\
\hline 27 & 255.7 & 253.54 & 255.7 & 208.13 & 255.7 & 255.58 & 255.56 & 255.66 & 255.7 \\
\hline 28 & 224.66 & 224.63 & 255.7 & 255.7 & 238.52 & 248.62 & 255.51 & 254.18 & 255.7 \\
\hline 29 & 255.7 & 255.37 & 255.69 & 255.7 & 254.53 & 252.77 & 217.13 & 255.66 & 255.7 \\
\hline 30 & 255.69 & 253.74 & 255.7 & 255.7 & 249.11 & 208.16 & 255.68 & 255.7 & 255.7 \\
\hline 31 & 255.69 & 242.7 & 255.69 & 255.7 & 253.52 & 255.7 & 222.84 & 255.67 & 255.7 \\
\hline 32 & 255.7 & 255.36 & 255.68 & 224.66 & 255.68 & 255.7 & 255.68 & 255.68 & 255.7 \\
\hline 33 & 255.7 & 253.13 & 255.7 & 255.7 & 253.83 & 255.55 & 255.58 & 255.65 & 255.7 \\
\hline 34 & 255.67 & 250.55 & 255.7 & 255.7 & 255.53 & 252.62 & 255.04 & 255.68 & 255.7 \\
\hline 35 & 255.7 & 255.7 & 255.7 & 255.7 & 253.22 & 255.7 & 252.81 & 255.7 & 255.7 \\
\hline 36 & 255.7 & 255.69 & 255.7 & 255.7 & 255 & 255.69 & 244.18 & 255.67 & 255.7 \\
\hline 37 & 255.7 & 240.7 & 224.66 & 255.7 & 255.66 & 255.7 & 254.97 & 255.66 & 255.7 \\
\hline 38 & 255.57 & 204.21 & 255.68 & 255.7 & 255.59 & 255.16 & 255.56 & 255.54 & 255.7 \\
\hline 39 & 255.7 & 255.59 & 255.68 & 255.7 & 254.5 & 255.67 & 255.1 & 255.57 & 255.7 \\
\hline 40 & 255.7 & 247.61 & 255.68 & 255.7 & 255.29 & 255.7 & 251.46 & 255.68 & 255.7 \\
\hline 41 & 242.32 & 240.79 & 255.69 & 224.66 & 254.79 & 255.63 & 252.78 & 255.65 & 255.7 \\
\hline 42 & 255.7 & 255.04 & 255.7 & 255.7 & 250.13 & 255.68 & 239.03 & 255.65 & 255.7 \\
\hline 43 & 224.66 & 253.26 & 255.56 & 255.7 & 253.23 & 255.7 & 253.5 & 255.59 & 255.7 \\
\hline 44 & 255.67 & 250.87 & 255.7 & 255.7 & 253.98 & 255.7 & 208.19 & 255.67 & 255.7 \\
\hline 45 & 255.69 & 249.81 & 255.69 & 255.7 & 254.91 & 255.65 & 255.67 & 255.69 & 255.7 \\
\hline 46 & 255.69 & 224.51 & 255.7 & 255.7 & 254.72 & 243.57 & 224.49 & 255.38 & 255.7 \\
\hline 47 & 255.7 & 255.68 & 255.7 & 255.7 & 255.53 & 255.7 & 255.7 & 255.69 & 255.7 \\
\hline 48 & 255.7 & 249.41 & 255.67 & 255.7 & 255.69 & 255.34 & 255.7 & 255.65 & 255.7 \\
\hline 49 & 255.7 & 255.6 & 255.7 & 255.7 & 254.35 & 255.68 & 249.91 & 255.39 & 255.7 \\
\hline 50 & 255.7 & 245.55 & 255.7 & 255.7 & 254.97 & 224.67 & 255.69 & 255.67 & 255.7 \\
\hline
\end{tabular}


Table 5: The detailed performance of each technique for the $2^{\text {nd }}$ shading scenario.

\begin{tabular}{|c|c|c|c|c|c|c|c|c|c|}
\hline Runs & DE & HSA & PSO & CS & SCA & GA & Bat & WDO & IWO \\
\hline 1 & 196.42 & 195.98 & 196.41 & 196.42 & 181.74 & 196.29 & 167.41 & 196.34 & 196.42 \\
\hline 2 & 196.4 & 184.81 & 196.17 & 196.42 & 196.37 & 196.27 & 170.68 & 196.08 & 196.42 \\
\hline 3 & 196.42 & 196.11 & 167.83 & 196.42 & 191.23 & 196.37 & 189.17 & 196.24 & 196.42 \\
\hline 4 & 167.88 & 188.84 & $\mathbf{1 9 6 . 4 2}$ & 167.88 & 195.39 & 196.33 & 167.88 & 195.92 & 196.42 \\
\hline 5 & 184.34 & 192.61 & 196.41 & 196.42 & 195.56 & 196 & 167.87 & 196.42 & 196.42 \\
\hline 6 & 167.88 & 195.62 & 196.42 & 196.42 & 191 & 196.42 & 155.15 & 196.41 & 196.42 \\
\hline 7 & 187.09 & 167.47 & 196.42 & 196.42 & 195.9 & 196.41 & 167.88 & 196.37 & 196.42 \\
\hline 8 & 194.41 & 194.98 & 196.41 & 196.42 & 190.84 & 195.1 & 196.12 & 196.41 & 196.42 \\
\hline 9 & 196.41 & 195.82 & 167.88 & 196.42 & 183.92 & 196.4 & 195.2 & 195.88 & 196.42 \\
\hline 10 & 196.42 & 196.41 & 167.88 & 196.42 & 196.32 & 196.42 & 196.21 & 196.42 & 196.42 \\
\hline 11 & 196.3 & 167.84 & 196.42 & 167.88 & 196.29 & 196.06 & 195.61 & 196.23 & 196.42 \\
\hline 12 & 196.42 & 195.47 & 196.42 & 167.88 & 196.39 & 167.88 & 166.68 & 196.37 & 196.42 \\
\hline 13 & 196.42 & 196.31 & $\mathbf{1 9 6 . 4 2}$ & 167.88 & 186.87 & 167.88 & 185.77 & 196.38 & 196.42 \\
\hline 14 & 196.42 & 189.96 & 196.41 & 196.42 & 167.14 & 196.36 & 162.22 & 196.42 & 196.42 \\
\hline 15 & 195.63 & 186.42 & 167.88 & 167.88 & 195.81 & 195.45 & 196.27 & 196.41 & 196.42 \\
\hline 16 & 196.42 & 195.89 & 196.42 & 196.42 & 195.98 & 194.41 & 166.55 & 196.42 & 196.42 \\
\hline 17 & 196.42 & 196.37 & 167.88 & 167.88 & 196.02 & 196.42 & 196.42 & 196.42 & 196.42 \\
\hline 18 & 196.42 & 196.41 & 196.42 & 196.42 & 196.24 & 196.4 & 196.27 & 196.41 & 196.42 \\
\hline 19 & 196.42 & 195.12 & 196.33 & 167.88 & 196.38 & 196.4 & 194.71 & 196.2 & 196.42 \\
\hline 20 & 196.42 & 193.71 & 196.41 & 196.42 & 195.54 & 196.2 & 194.77 & 196.4 & 196.42 \\
\hline 21 & 196.42 & 196.37 & 167.87 & 196.42 & 196.38 & 167.84 & 195.21 & 196.28 & 196.42 \\
\hline 22 & 196.41 & 193.2 & 167.88 & 196.42 & 196.38 & 196.42 & 190.01 & 196.38 & 196.42 \\
\hline 23 & 196.41 & 186.2 & 196.42 & 196.42 & 196.42 & 167.88 & 196.38 & 167.85 & 196.42 \\
\hline 24 & 196.42 & 144.43 & 196.4 & 196.42 & 195.98 & 167.84 & 192.93 & 196.39 & 196.42 \\
\hline 25 & 196.42 & 192.85 & 196.42 & 196.42 & 195.12 & 196.42 & 172.61 & 195.78 & 196.42 \\
\hline 26 & 196.42 & 196.01 & 196.41 & 196.42 & 196.27 & 196.41 & 181.26 & 196.4 & 196.42 \\
\hline 27 & 191.14 & 176.35 & 196.4 & 196.42 & 164.55 & 196.31 & 166.77 & 196.38 & 196.42 \\
\hline 28 & 196.42 & 184.83 & 196.31 & 196.42 & 195.96 & 196.42 & 167.88 & 196.34 & 196.42 \\
\hline 29 & 196.42 & 196.37 & 167.87 & 196.42 & 195.96 & 194.03 & 192.99 & 196.4 & 196.42 \\
\hline 30 & 194.41 & 196.33 & 196.42 & 196.41 & 194.73 & 196.39 & 167.8 & 196 & 196.42 \\
\hline 31 & 196.37 & 196.01 & 196.41 & 196.42 & 195.96 & 193.21 & 195.64 & 196.42 & 196.42 \\
\hline 32 & 196.42 & 196.02 & 196.28 & 196.42 & 196.38 & 196.34 & 196.41 & 196.4 & 196.42 \\
\hline 33 & 196.42 & 167.77 & 196.42 & $\mathbf{1 9 6 . 4 2}$ & 196.33 & 196.42 & 195.77 & 196.42 & 196.42 \\
\hline 34 & 196.41 & 158.46 & 196.41 & 167.88 & 193.63 & 196.42 & 167.88 & 196.34 & 196.42 \\
\hline 35 & 196.33 & 196.41 & 196.42 & 167.88 & 192.85 & 196.42 & 195.07 & 196.41 & 196.42 \\
\hline 36 & 196.4 & 188.66 & 167.87 & 167.88 & 196.36 & 196.17 & 196.19 & 196.4 & 196.42 \\
\hline 37 & 196.41 & 159.38 & 196.4 & 196.42 & 195.61 & 196.41 & 192.91 & 196.4 & 196.42 \\
\hline 38 & 196.41 & 172.51 & 167.88 & 167.88 & 195.41 & 195.52 & 192.14 & 196.16 & 196.42 \\
\hline 39 & 196.29 & 194.46 & 196.42 & 196.42 & 189.22 & 167.88 & 172.4 & 196.32 & 196.42 \\
\hline 40 & 196.42 & 195.09 & 167.88 & 196.42 & 192.92 & 196.4 & 167.37 & 196.41 & 196.42 \\
\hline 41 & 196.33 & 192.68 & 196.42 & 196.42 & 189.5 & 167.88 & 195.73 & 196.34 & 196.42 \\
\hline 42 & 167.88 & 196.17 & 196.41 & 196.42 & 167.84 & 167.88 & 186.41 & 196.35 & 196.42 \\
\hline 43 & 195.84 & 189.53 & 196.42 & 196.42 & 192.67 & 193.83 & 196.42 & 196.41 & 196.42 \\
\hline 44 & 192.29 & 181.69 & 167.86 & 196.42 & 196.38 & 196.41 & 166.19 & 196.36 & 196.42 \\
\hline 45 & 196.41 & 196.31 & 167.88 & 196.42 & 195.3 & 196.42 & 182.32 & 167.88 & 196.42 \\
\hline 46 & 196.19 & 191.4 & 167.88 & 196.42 & 196.4 & 196.42 & 191.57 & 196.41 & 196.42 \\
\hline 47 & 196.25 & 194.19 & 196.42 & 167.88 & 195.58 & 196.34 & 191.56 & 195.07 & 196.42 \\
\hline 48 & 196.39 & 160.37 & 196.42 & 196.42 & 195.67 & 167.88 & 187.24 & 194.99 & 196.42 \\
\hline 49 & 196.41 & 196.39 & 196.42 & 196.42 & 196.35 & 196.38 & 193.33 & 196.41 & 196.42 \\
\hline 50 & 171.28 & 174.17 & 196.32 & 167.88 & 196.4 & 178.74 & 192.33 & 196.35 & 196.42 \\
\hline
\end{tabular}


Table 6: The number of reaches to GMPP for each technique.

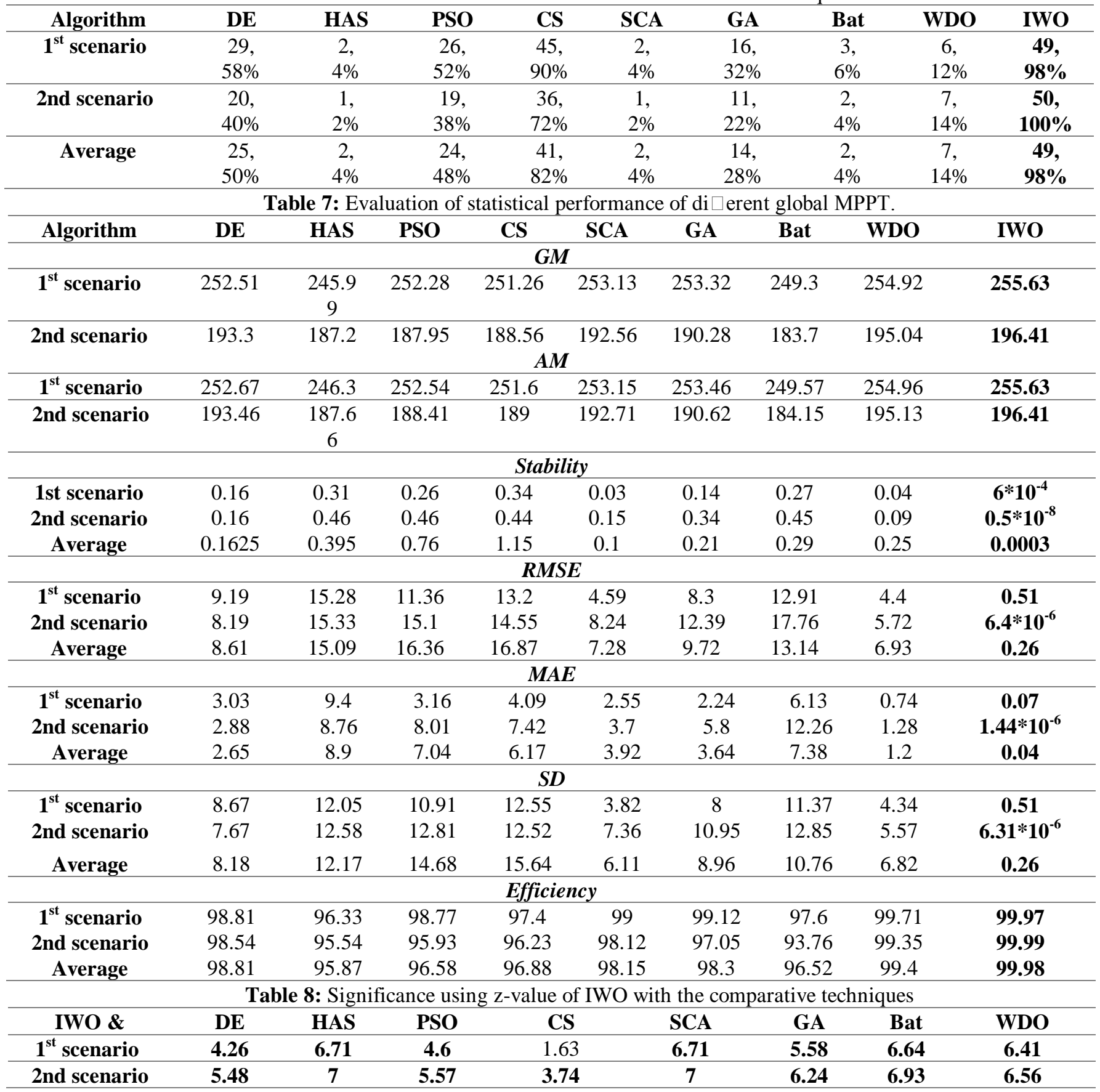

Table 4 shows the GMPP for the $1^{\text {st }}$ shading scenario in the 50 runs in which the IWO technique reaches the theoretical GMPP (255.7) in 49 of 50 runs flowed by CS technique reaches the theoretical GMPP (255.7) in 45 of 50 runs which is trapped in LMMPs in 5 runs.

Table 5 shows the GMPP for the $2^{\text {nd }}$ shading scenario in the 50 runs in which the IWO technique reaches the theoretical GMPP (196.41) in the 50 runs flowed by CS technique reaches it in 36 of 50 runs.
Table 6 shows the number of reaches to GMPP for each technique. The first four successful techniques reaching the theoretical GMPP are IWO (98\%), CS (82\%), DE (50\%) and PSO $(48 \%)$ on the average.

Table 7 shows that IWO has the nearest values of GM and AM to exact values, compared with the three other techniques. For example, in the $1^{\text {st }}$ scenario GM and AM equal (255.63) which are the nearest value compared to the other techniques to the GMMP (255.7). Also, IWO has the highest stability as the difference between AM and GM is approximately zero. IWO has the smallest values of MAE, SD 
and RMSE of all successful techniques. The e $\square$ ciency of IWO is $99.98 \%$ which is the highest one compared with the all other techniques.

Table 8 shows Significance using $\mathrm{z}$ value of IWO with the comparative techniques. When the $\mathrm{z}$ value is higher than 1.96, this indicates that there is a significance between the IWO and the comparative technique. Table 10 shows that IWO has significant differences in 15 out of 16 cases with percentage $93.75 \%$.

\section{CONCLUSION}

This paper presents an efficient and a robust GMPPT technique based on invasive weed optimization (IWO) algorithm for PV system under PSCs. To ensure the effectiveness of IWO, a comprehensive comparison between the proposed IWO and previously developed techniques such as PSO, DE, HSA, Bat, SCA, WDO, CS and GA is carried out under di $\square$ erent shading scenarios. Eight statistical measures show that IWO is more efficient, stable and accurate than the other techniques. Ultimately, it can be concluded that, IWO is the best optimization technique compared with the others.

\section{REFERENCES}

[1] Muhammad Ammirrul Atiqi Mohd Zainuri, Ezril Aidil Azari, Ahmad Asrul Ibrahim, et al. Analysis of Adaptive Perturb and Observe-Fuzzy Logic Control Maximum Power Point Tracking for Photovoltaic Boost DC-DC Converter, International Journal of Advanced Trends in Computer Science and Engineering, 2019, pp. 201-210.

[2] Jirada Gosumbonggot and Goro Fujita. Partial Shading Detection and Global Maximum Power Point Tracking Algorithm for Photovoltaic with the Variation of Irradiation and Temperature, MDPI (Energies), 2019, pp. 1-22.

[3] Bo Xing and Wen-Jing Gao. Innovative Computational Intelligence: A Rough Guide to 134 Clever Algorithms, London: Springer, (62), 2014.

[4] Ali M. Eltamaly, Hassan M.H. Farh and Mamdooh S. Al-Saud. Grade point average assessment for metaheuristic GMPP techniques of partial shaded PV systems, IET Renewable Power Generation, 2019, pp. 1-17.

[5] Mouna BEN SMIDA, Anis SAKLY. Genetic based algorithm for maximum power point tracking (MPPT) for grid connected PV systems operating under partial shaded conditions, $7^{\text {th }}$ International Conference on Modelling, Identification and Control, December 18-20, 2015, pp. 1-6.

[6] Maneesha Dwivedi, Dr. Gitanjali Mehta, Asif Iqbal, et.al. Performance enhancement of solar PV system under Partial Shaded Condition using
PSO, $8^{\text {th }}$ International Conference on Communication and Network Technology, July 3-5, 2017, pp. 2-7.

[7] Kok Soon Tey, Saad Mekhilef, Hong-Tzer Yang, et.al. A Differential Evolution Based MPPT Method for Photovoltaic Modules under Partial Shading Conditions, International Journal of Photoenergy, 2014, pp. 1-10.

[8] Othman A.M.Omar, Niveen M. Badra, Mahmoud A. Atti. Enhancement of On-grid PV System under Irradiance and Temperature Variations Using New Optimized Adaptive Controller, International Journal of Electrical and Computer Engineering, 2017, pp. 2650-2660.

[9] Mohamed I. Mosaad, M. Osama abed el-Raouf, Mahmoud A. Al-Ahmar, et al. Maximum Power Point Tracking of PV system Based Cuckoo Search Algorithm; review and comparison, ELSEVIER (Energy Procedia), 2019, pp. 117-126.

[10] Mehdi Seyedmahmoudian, Tey Kok Soon, Elmira Jamei, et.al. Maximum Power Point Tracking for Photovoltaic Systems under Partial Shading Conditions Using Bat Algorithm. MDPI (sustainability), 2018, pp. 1-16.

[11] Omer Abdalla, Hegazy Rezk, and Emad M. Ahmed. Wind driven optimization algorithm based global MPPT for PV system under non-uniform solar irradiance, ELSEVIER (Solar Energy), 2019, pp. 429-444.

[12] Sanjeevikumar Padmanaban, Neeraj Priyadarshi, Jens Bo Holm-Nielsen, et al. A Novel Modified Sine-Cosine Optimized MPPT Algorithm for Grid Integrated PV System under Real Operating Conditions, IEEE (Translations and content mining are permitted for academic research), 2018, pp. 1-11.

[13] Zhongshi Shao, Dechang Pi, Weishi Shao, et.al. An efficient discrete invasive weed optimization for blocking flow-shop scheduling problem, Elsevier (Engineering Applications of Artificial Intelligence), 2019, pp. 124-141.

[14] Faiza Belhachat, and Cherif Larbe. Analysis and Design of a Maximum Power Point Tracker for a Stand-Alone Photo Voltaic System Using Simscape, International Journal of Advanced Trends in Computer Science and Engineering, 2019, pp. 54-57.

[15] Mehmet BEŞKİRLİ, İsmail KOÇ, Halife KODAZ. Optimal Placement of Wind Turbines Using Novel Binary Invasive Weed Optimization, Technical Gazette, 2019, (26), pp. 56-63.

[16] J. Midhunchakkaravarthy, S. Selva Brunda. A novel approach for feature fatigue analysis using HMM stemming and adaptive invasive weed optimization with hybrid firework optimization method, Int. J. Computer Aided Engineering and 
Technology, 2019, (11), pp. 411-429.

[17] $\mathrm{Lu} \mathrm{Hu}$, Fei Xue, Zijian Qin. Sliding mode extremum seeking control based on improved invasive weed optimization for MPPT in wind energy conversion system, Elsevier (Applied Energy), 2019, (248), pp. 567-575.

[18] Li Li, Hongwei Ge, Jianqiang Gao, et.al. A Novel Geometric Mean Feature Space Discriminant Analysis Method for Hyperspectral Image Feature Extraction, Springer (Neural Processing Letters), 2019, pp. 1-28.

[19] Y.Q. Wang, Z.F. Shang, M. Yue, et.al. Correlation between $\mathrm{Fe}$ content and $\mathrm{z}$ value in $\mathrm{Sm}\left(\mathrm{Co}_{\text {bal }} \mathrm{Fe}_{\mathrm{x}} \mathrm{Cu}_{0.06} \mathrm{Zr}_{0.025}\right)_{\mathrm{z}}$ permanent magnets, Journal of Magnetism and Magnetic Materials, 2019, pp. 1-20. 